\title{
Assessment of Seasonal and Annual Rainfall Trends and Variability in Sharjah City, UAE
}

\author{
Tarek Merabtene, Mohsin Siddique, and Abdallah Shanableh \\ Department of Civil and Environmental Engineering, University of Sharjah, Sharjah, UAE \\ Correspondence should be addressed to Tarek Merabtene; tmerabtene@sharjah.ac.ae
}

Received 13 April 2016; Accepted 14 July 2016

Academic Editor: Marina Baldi

Copyright ( 2016 Tarek Merabtene et al. This is an open access article distributed under the Creative Commons Attribution License, which permits unrestricted use, distribution, and reproduction in any medium, provided the original work is properly cited.

\begin{abstract}
Although a few studies on rainfall spatial and temporal variability in the UAE have been carried out, evidence of the impact of climate change on rainfall trends has not been reported. This study aims at assessing the significance of long-term rainfall trends and temporal variability at Sharjah City, UAE. Annual rainfall and seasonal rainfall extending over a period of 81 years (19342014) recorded at Sharjah International Airport have been analyzed. To this end, several parametric and nonparametric statistical measures have been applied following systematic data quality assessment. The analyses revealed that the annual rainfall trend decreased from $-3 \mathrm{~mm}$ to $-9.4 \mathrm{~mm}$ per decade over the study periods. The decreasing annual rainfall trend is mainly driven by the significant drop in winter rainfall, particularly during the period from 1977 to 2014 . The results also indicate that high probability extreme events have shifted toward low frequency (12.7 years) with significant variations in monthly rainfall patterns and periodicity. The findings of the present study suggest reevaluating the derivation of design rainfall for infrastructure of Sharjah City and urge developing an integrated framework for its water resources planning and risk under climate change impacts scenarios.
\end{abstract}

\section{Introduction}

Recent global changes in climate have resulted in increased variability of the hydrological cycle and weather extremes, creating the need to study subsequent changes in hydroclimatic variables to understand the regional effects of climate change $[1,2]$. International and regional assessment reports on climate change (e.g., [3-6]) classify the Middle East and North Africa (MENA) as one of the most vulnerable regions to be affected by climate change and climate extremes. Pal and Eltahir [7] claim that the situation in the Arabian Gulf region, especially changes in extreme climates, is at risk of magnification to unprecedented levels under the predicted regional climate change scenarios. Nevertheless, while climate change is seen as a fact, the reality about the current predictions for the region is highly uncertain. To date, for most Middle East countries, only little is known about the significance of the trends and variability in hydroclimatic data. Several studies have compared simulated climatic data with observed data to assess climate models uncertainty (e.g., [8-11]). Their works concluded that existing climate models have difficulties to accurately simulate present extreme climate events and these provide additional uncertainty to predict future changes. Therefore, the importance of continuously assessing the longterm variability and short-term variability of climatic factors, mainly those connected to the availability of fresh water, using in situ climatic data cannot be overemphasized [9, 1215].

Worldwide, several studies have engaged in assessing the trends and variability in hydrometeorological data, mainly rainfall and temperature, at regional level (e.g., [18-20]) as well as country levels (e.g., [11, 13, 14, 18, 21-26]) to mention only very few contributions. In contrast, for many of the Middle East countries, mainly arid and semiarid regions such as the Gulf peninsula, research coverage is still inadequate despite recent works [20]. Studies over Oman $[27,28]$ showed statistically significant decreasing trends in rainfall. However, the results of the two studies also suggest a significant tendency for stronger precipitation extremes as well as a tendency toward wetter conditions. The findings of some studies over several regions of Iran [29-31] showed no negative or positive annual rainfall trends throughout the 
country, except for some local and isolated stations. However, monthly rainfall trends were identified with appearing seasonal movement of rainfall concentration. The investigations of Almazroui et al. [32] and Hasanean and Almazroui [33] revealed large interannual variability in the precipitation over Saudi Arabia, with a rainfall reduction ranging from $6 \mathrm{~mm}$ to $47 \mathrm{~mm}$ per decade, at the expectation of the Southern Peninsula and along the Red Sea coast, where an increase in precipitation was observed. The study of Al-Mamoon and Rahman [34] over Qatar showed both positive and negative trends throughout the country. While the negative trends were found to be statistically significant in a number of stations, the stations with positive trends were statistically not significant.

In UAE, while few studies have been carried out with emphasis on the status of water resources (e.g., [35-40]) and on UAE climate [41, 42], quantitative evidence of trends in rainfall and temporal variability due to climate change based on long-term rainfall records has not been reported. This study investigates the long-term rainfall trends and variability in Sharjah City, UAE. While climate variability is regarded as the deviation of seasonal and annual climate parameters (i.e., rainfall, temperature, etc.) from the long-term observations mean, the long-term continuous temporal change and/or trends in annual, seasonal, and monthly climate parameters (herein rainfall) are regarded as indicators of potential climate change impacts [43]. Previous studies assert that long-term change (30 years and above) in rainfall and temperature are considered as valuable indicators to assess the potential of climate change in a given region [24, 32, 44, 45]. The processed data consist of monthly and annual rainfall extending over a period of 81 years (1934-2014) recorded at the Sharjah International Airport. Following a data quality assessment, parametric and nonparametric tests were applied to examine and quantify the long-term and short-term trends and variability in annual, seasonal, and monthly rainfalls. Variability in extreme events and changes in frequency (i.e., return period) were also examined to assess any potential shift in wet and dry seasons.

\section{Materials and Methods}

2.1. Study Area and Data Quality Control. The Emirate of Sharjah is the third largest emirate of the UAE, covering a total area of about $2,600 \mathrm{~km}^{2}$. The meteorological data for Sharjah are maintained by the Sharjah Meteorological Office since 1934. The present assessment is based on rainfall data over a period of 81 years (1934-2014), representing the longest period ever investigated for the Gulf region to date. Data covering the period from 1934 to 1976 were recorded at the old Sharjah airport, while rainfall data from 1977 onwards are recorded at the new Sharjah International Airport [42]. The locations of old airport $\left(25.349485^{\circ} \mathrm{N}, 55.3875036^{\circ} \mathrm{E}\right)$ and new Sharjah International Airport $\left(25.329167^{\circ} \mathrm{N}, 55.516111^{\circ} \mathrm{E}\right)$ are approximately $8 \mathrm{Km}$ apart. It is clear that while rainfall events are influenced by regional and global weather pattern, the temporal and spatial variation and distribution (i.e., rainfall intensity and duration) over a given geographical region stay influenced by local parameters. It can, therefore, be assumed

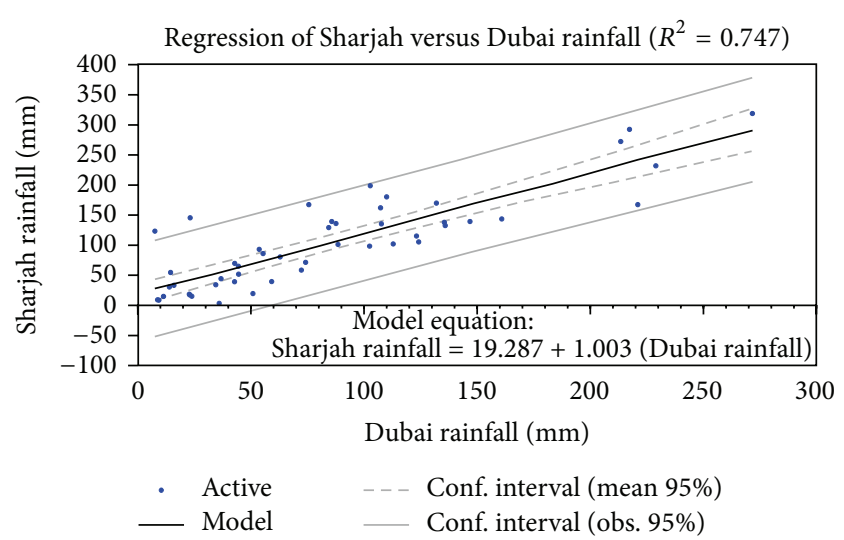

FIGURE 1: Linear regression of Sharjah versus Dubai and its model equation.

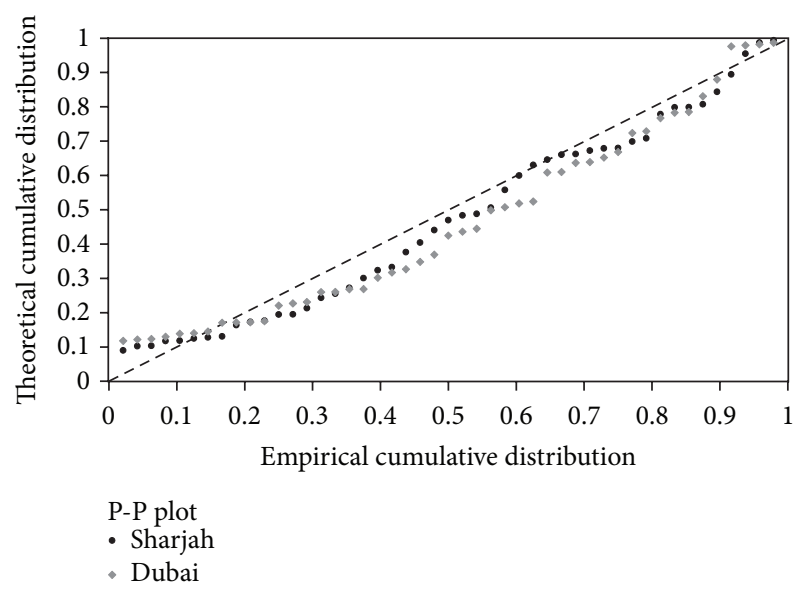

FIGURE 2: Cumulative probability distribution of Sharjah versus Dubai.

that the rainfall records at those two stations (in proximity) may not record exactly same rainfalls (noticing also the changes in measurement devices and technology) but most likely exhibit consistency in rainfall patterns and trends.

2.1.1. Overall Data Quality Assessment. To assess the overall quality of the rainfall data recorded at Sharjah airport, the mean annual rainfall recorded between 1966 and 2014 at Dubai airport (i.e., located $20 \mathrm{~km}$ away from Sharjah Airport) was used as a quality control indicator. Despite the fact that both stations are physically independent, the rainfall in Sharjah and Dubai is governed by similar weather patterns and mechanisms [41]. Therefore, good correlation between the two rainfall data sets would be an acceptable indicator to validate data consistency. To this end, linear regression analysis and the nonparametric two-sample Kolmogorov-Smirnov (KS) regression test [46-48] were performed. The results of the linear regression analysis (Figure 1) and corresponding cumulative probability distribution (Figure 2) probably suggest good correlation between the two rainfall data series (i.e., Sharjah versus Dubai). To verify it, two-sample KolmogorovSmirnov (KS) test (i.e., Sharjah versus Dubai rainfall) using 


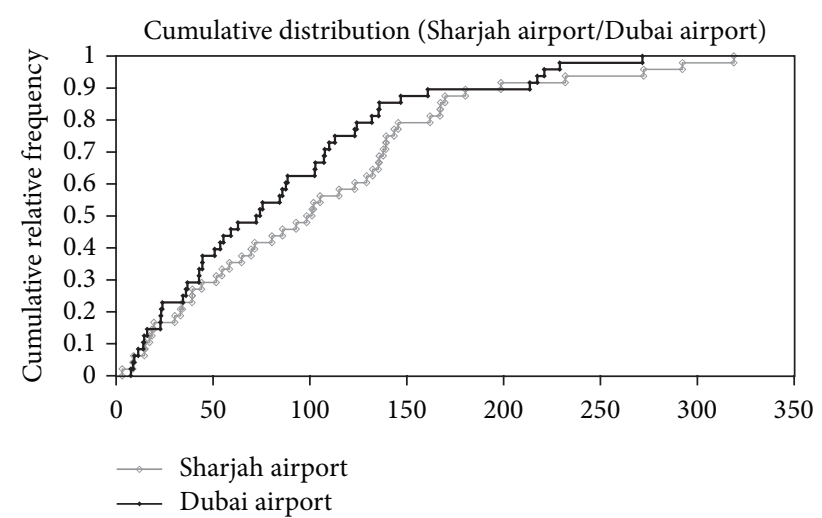

FIgURE 3: Comparison of Sharjah and Dubai airports' rainfall distributions using Kolmogorov-Smirnov cumulative frequency distribution.

multiple hypothesized difference and significance levels was performed. From the KS test result (Figure 3), the maximum difference between the cumulative distributions, $D$, was in the range $[0.188,0.208]$ with a corresponding $p$ value of $[0.371,0.249]$. The high probability $p$ value suggests accepting the alternative hypothesis that Sharjah and Dubai rainfall time series follow the same distribution. Therefore, it was concluded that the quality of rainfall data records at Sharjah airport was consistent and eligible for further data quality analysis without corrections.

2.1.2. Homogeneity Analysis. Homogeneity analysis is critical to assure that detected changes and trends in rainfall data series are essentially due to climate and weather [49]. Inhomogeneity of Sharjah climate data records was suspected, primarily due to the changes in the station location from the old airport (1934-1976) to the new airport (1977-2014) and/or secondarily due to the changes in measurement methods, especially instruments technology and exposure of the new station. The homogeneity analysis was conducted based on four measures, namely, the Standard Normal Homogeneity Test (SNHT), Buishand's range test, Pettitt's test, and von Neumann's test. The methodologies of the measures are lengthily presented in Alexandersson [50], Hirsch et al. [51], Peterson et al. [49], and Kang and Yusof [52]. The aforementioned measures correspond to the alternative hypothesis of a single shift. $p$ values of the tests' statistic were evaluated using the standard method (SM) and Monte Carlo Simulation (MCS), except for SNHT, where only MCS was used [53].

The measures were applied to the entire period (81-year annual data) and five aggregated periods: 1934-1976 (the old airport data), 1977-2014 (the new airport data), 1934-1964, 1960-1990, and 1984-2014. The statistical comparisons of the measures are shown in Table 1 . The homogeneity results over the entire period are unclear as the outcomes of the measures (i.e., $p$ value) obtained by the standard method (SM) contradict those obtained by Monte Carlo Simulation (MCS). The exception is found for von Neumann's test, where the null hypothesis (i.e., data are homogeneous) is rejected by both methods of calculation (SM and MCS). For the records

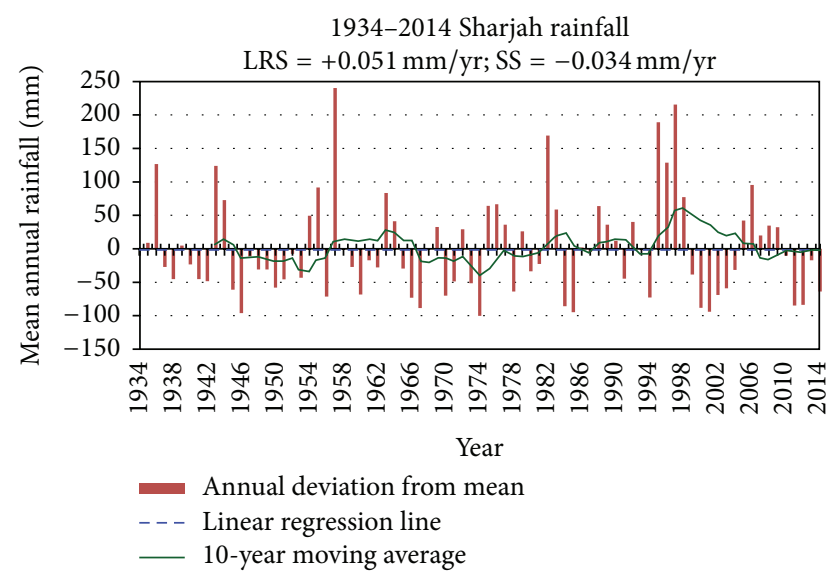

FIgURE 4: Deviation of annual rainfall from the mean and corresponding linear regression and 10 -year moving average lines.

from the old Sharjah airport (1934-1976) and the new Sharjah airport (1977-2014), all tests' results are to accept the null hypothesis. Identified break points (at years 1944, 1964, 1974, 1998, and 2010) match those of Dubai airport's data, thus excluding the probability of bias due to physical factors. The visual plot (Figure 4) shows that they are driven by an abrupt shift from successive wet years to successive dry years.

For the rest of this study, in order to significantly analyze the rainfall variability and trends, it was proposed to assess the entire period in addition to five aggregated periods: the old Sharjah airport data set (1934 to 1976), the new Sharjah airport data set (1977 to 2014), and three overlapping 31-year data sets. Homogeneity analysis was also carried out on these three aggregated periods (Table 1). The conclusions from the different methods were at most coherent. An exception was for the period of 1934-1964, where $p$ values estimates by MCS and SM were not in agreement. For this particular period, most tests using MCS exclusively suggest that the data are homogenous (denoted in Table 1 as "Yes: MCS"). As a matter of fact, many historical extremes have occurred during that period, which was particularly characterized by an increasing rainfall trend as further discussed in the next section.

The weather in UAE can be divided into four seasons, namely, winter from December to March, spring from April to May, summer from June to September, and autumn from October to November [41]. Winter is the most unsettled period of the year. Winter rains usually start in late November or early December and extend through March bringing approximately over $80 \%$ of the annual rainfall with a monthly average of about $25 \mathrm{~mm}$. Spring is short and rainfall is sporadic, typically linked with isolated thunderstorms. Summer is characterized by extremely dry condition with rare chances of rainfall. Autumn months represent the most settled weather conditions and rainfall is again rare, especially in October [42]. Table 2 shows a comparison of basic monthly rainfall statistics over the different aggregated study periods.

2.2. Annual and Seasonal Analysis of Trends and Variability. Trends and variability in annual and seasonal weather data 
TABLE 1: Homogeneity tests (two-tailed, $\alpha=5 \%$ ) of Sharjah annual rainfall applied to different aggregated periods.

\begin{tabular}{|c|c|c|c|c|c|}
\hline \multirow{2}{*}{ Annual rainfall period } & \multirow{2}{*}{ Statistical measures } & \multicolumn{2}{|c|}{$p$ value estimation } & \multirow{2}{*}{ Data homogeneity } & \multirow{2}{*}{ Year of break point } \\
\hline & & SM & MCS & & \\
\hline \multirow{4}{*}{ 1934-2014 } & SNHT & - & 0.683 & Yes & 2010 \\
\hline & Pettitt's & $<0.001$ & 0.781 & Yes: MCS* & 1998 \\
\hline & Buishand's & $<0.001$ & 0.739 & Yes: MCS & 1998 \\
\hline & von Neumann's & $<0.001$ & 0.014 & No & - \\
\hline \multirow{4}{*}{$\begin{array}{l}\text { 1934-1976 } \\
\text { Old Sharjah airport }\end{array}$} & SNHT & - & 0.787 & Yes & 1974 \\
\hline & Pettitt's & 1.756 & 0.652 & Yes & 1944 \\
\hline & Buishand's & 1.756 & 0.936 & Yes & 1964 \\
\hline & von Neumann's & 1.756 & 0.406 & Yes & - \\
\hline \multirow{4}{*}{$\begin{array}{l}\text { 1977-2014 } \\
\text { New Sharjah Airport }\end{array}$} & SNHT & - & 0.365 & Yes & 1998 \\
\hline & Pettitt's & 0.42 & 0.215 & Yes & 1998 \\
\hline & Buishand's & 0.42 & 0.15 & Yes & 1998 \\
\hline & von Neumann's & 0.42 & 0.003 & Yes: $\mathrm{SM}^{* *}$ & - \\
\hline \multirow{4}{*}{ 1934-1964 } & SNHT & - & 0.788 & Yes & 1953 \\
\hline & Pettitt's & 0.022 & 0.766 & Yes: MCS & 1953 \\
\hline & Buishand's & 0.022 & 0.592 & Yes: MCS & 1953 \\
\hline & von Neumann's & 0.022 & 0.515 & Yes: MCS & - \\
\hline \multirow{4}{*}{ 1960-1990 } & SNHT & - & 0.537 & Yes & 1974 \\
\hline & Pettitt’s & 0.295 & 0.305 & Yes & 1974 \\
\hline & Buishand's & 0.289 & 0.29 & Yes & 1974 \\
\hline & von Neumann's & 0.138 & 0.141 & Yes & - \\
\hline \multirow{4}{*}{ 1984-2014 } & SNHT & - & 0.417 & Yes & 1998 \\
\hline & Pettitt's & 1.596 & 0.32 & Yes & 1998 \\
\hline & Buishand's & 1.596 & 0.187 & Yes & 1998 \\
\hline & von Neumann's & 1.596 & 0.001 & Yes: SM & - \\
\hline
\end{tabular}

${ }^{*}$ Yes: MCS: if the homogeneity is exclusively valid using Monte Carlo Simulation (MCS). ${ }^{* *}$ Yes: SM: if the homogeneity test is exclusively valid using standard method (SM).

series are commonly assessed using parametric and nonparametric statistical measures [51]. In climate research, both approaches are equally beneficial; while parametric measures can generate an overall view of the trend and its tendency, nonparametric tests have the extra power to detect trends with seasonal variations $[21,54,55]$.

2.2.1. Analysis of Annual Rainfall Trends. Trend statistical measures imply testing the null hypothesis Ho (that there is no trend) against the alternative hypothesis $\mathrm{Ha}$ (that there is a trend) for a chosen significance level $\alpha$. Applied parametric measure considers linear regression on annual, seasonal, and monthly rainfall. Slope coefficients of the fitted linear regression models were evaluated following Student's $t$ distribution. If slope magnitude is significantly different from zero, then the alternative hypothesis shall be accepted. Positive or negative tendency of the trend is indicated by the sign of the slope coefficient [51].

Nonparametric measure considers Mann-Kendall (MK) test (see, e.g., $[14,54,56])$ powered by Sen's slope to quantify the magnitudes of the trends [57]. Since the MK test does not require that the data series follow a specific probability distribution, the identified monotonic trend, if any, can be linear or nonlinear $[54,58]$. To overcome the uncertainty in trend identification that could be mainly caused by the existence of significant autocorrelation, Hamed and Rao [17] propose improving the standard MK test by checking for serial correlation between the ranks of the data after eliminating the suspected trend. Their approach ensures that the identified trend, if any, is not essentially due to autocorrelation. A further improvement of the test was proposed by Yue and Wang [16] in case a serial correlation was found. Their approach performs better when there are both a trend and an autocorrelation. In this work, the standard MK test and the above two proposed improvements were performed in parallel to assess annual and seasonal aggregated data sets.

2.2.2. Analysis of Monthly Trends and Variability. Seasonal Mann-Kendall (S-MK) test [51, 56] was performed with and without taking into account autocorrelation effect to assess changes in monthly trends and variability. The SMK test suggests finding whether there is a trend from one given month, say January, to another and from one month, February, to another and so on. Choosing between the standard MK test and modified S-MK with autocorrelation, for monthly data with seasonality of 12 months, involves a 
TABLE 2: Average statistics of seasonal rainfall average (avg.), maximums (max.), and standard deviations (STD) in mm for different aggregated data sets.

\begin{tabular}{|c|c|c|c|c|c|c|c|c|c|c|c|c|c|}
\hline & & \multicolumn{4}{|c|}{ Winter rainfall $[\mathrm{mm}]$} & \multicolumn{2}{|c|}{$\begin{array}{l}\text { Spring rainfall } \\
{[\mathrm{mm}]}\end{array}$} & \multicolumn{4}{|c|}{ Summer rainfall $[\mathrm{mm}]$} & \multicolumn{2}{|c|}{$\begin{array}{c}\text { Autumn rainfall } \\
{[\mathrm{mm}]}\end{array}$} \\
\hline & & Dec. & Jan. & Feb. & Mar. & Apr. & May & Jun. & Jul. & Aug. & Sep. & Oct. & Nov. \\
\hline \multirow{3}{*}{ 1934-1964 } & Avg. & 26.4 & 24.1 & 17.2 & 9.3 & 8.7 & 4.2 & 0.0 & 0.9 & 0.0 & 0.2 & 0.5 & 13.4 \\
\hline & Max. & 174.0 & 95.1 & 106.0 & 50.1 & 152.0 & 120.6 & 0.0 & 15.6 & 0.3 & 5.4 & 15.6 & 113.0 \\
\hline & STD & 37.0 & 28.3 & 25.8 & 12.8 & 27.3 & 21.3 & 0.0 & 3.1 & 0.1 & 1.0 & 2.8 & 26.8 \\
\hline \multirow{3}{*}{ 1960-1990 } & Avg. & 12.7 & 20.6 & 26.8 & 21.0 & 7.0 & 4.6 & 0.0 & 0.3 & 0.1 & 0.0 & 0.6 & 4.3 \\
\hline & Max. & 75.0 & 167.4 & 142.9 & 156.4 & 37.7 & 120.6 & 0.0 & 8.3 & 2.4 & 0.0 & 19.5 & 41.6 \\
\hline & STD & 21.1 & 36.4 & 38.9 & 36.6 & 9.5 & 21.5 & 0.0 & 1.5 & 0.4 & 0.0 & 3.4 & 10.5 \\
\hline \multirow{3}{*}{ 1984-2014 } & Avg. & 22.0 & 17.7 & 19.6 & 25.4 & 7.1 & 0.1 & 1.0 & 2.8 & 0.0 & 2.2 & 2.0 & 4.7 \\
\hline & Max. & 146.5 & 97.8 & 142.9 & 152.6 & 59.9 & 3.0 & 29.6 & 53.1 & 0.6 & 59.9 & 63.4 & 43.4 \\
\hline & STD & 35.8 & 24.1 & 31.7 & 39.7 & 13.0 & 0.6 & 5.2 & 10.7 & 0.1 & 10.7 & 11.2 & 10.6 \\
\hline \multirow{3}{*}{$1986-2014$} & Avg. & 23.1 & 18.8 & 21.0 & 26.8 & 7.6 & 0.1 & 1.0 & 2.9 & 0.0 & 2.4 & 2.2 & 5.0 \\
\hline & Max. & 146.5 & 97.8 & 142.9 & 152.6 & 59.9 & 3.0 & 29.6 & 53.1 & 0.6 & 59.9 & 63.4 & 43.4 \\
\hline & STD & 36.7 & 24.6 & 32.4 & 40.6 & 13.3 & 0.6 & 5.4 & 11.0 & 0.1 & 11.0 & 11.6 & 10.9 \\
\hline \multirow{3}{*}{ 1977-2014 } & Avg. & 16.3 & 22.9 & 29.3 & 7.8 & 0.7 & 0.8 & 2.2 & 0.0 & 1.8 & 1.7 & 5.3 & 20.1 \\
\hline & Max. & 97.8 & 142.9 & 156.4 & 59.9 & 20.6 & 29.6 & 53.1 & 0.6 & 59.9 & 63.4 & 43.4 & 146.5 \\
\hline & STD & 22.7 & 32.6 & 42.2 & 13.1 & 3.3 & 4.7 & 9.7 & 0.1 & 9.7 & 10.1 & 11.6 & 33.6 \\
\hline \multirow{3}{*}{ 1934-1976 } & Avg. & 27.5 & 18.2 & 10.0 & 7.4 & 3.1 & 0.0 & 0.6 & 0.1 & 0.1 & 0.8 & 10.3 & 20.1 \\
\hline & Max. & 167.4 & 128.2 & 114.8 & 152.0 & 120.6 & 0.0 & 15.6 & 2.4 & 5.4 & 19.5 & 113.0 & 174.0 \\
\hline & STD & 36.5 & 30.1 & 19.9 & 23.5 & 18.2 & 0.0 & 2.7 & 0.4 & 0.8 & 3.7 & 23.6 & 33.3 \\
\hline \multirow{3}{*}{ 1934-2014 } & Avg. & 22.2 & 20.4 & 19.0 & 7.6 & 1.9 & 0.4 & 1.4 & 0.0 & 0.9 & 1.2 & 8.0 & 20.1 \\
\hline & Max. & 167.4 & 142.9 & 156.4 & 152.0 & 120.6 & 29.6 & 53.1 & 2.4 & 59.9 & 63.4 & 113.0 & 174.0 \\
\hline & STD & 31.3 & 31.4 & 33.7 & 19.3 & 13.5 & 3.3 & 7.0 & 0.3 & 6.7 & 7.5 & 19.1 & 33.4 \\
\hline
\end{tabular}

trade-off. The standard MK test is more powerful, but the results interpretation can be misleading if there is a seasonal serial correlation, that is, the correlation of a given month with preceding months. However, the modified test, though less powerful, offers a more rigorous statement of significance [59]. Trends magnitudes were assessed using Sen's slope and seasonal Sen's slope [56]. The changes in extreme rainfalls and frequency were evaluated using exceedance probability and Fast Fourier Transform [60, 61].

The theoretical background and methodologies of the statistical measures involved in this study are not repeated here. Readers are primarily referred to Hirsch et al. [51] and WMO [62]. Brief descriptions were also presented in many of the aforementioned literatures in this chapter.

\section{Results and Discussion}

3.1. Annual Trend Analysis Results. To fully explore rainfall variations and trends essentially triggered by climate change, the assessment was conducted for the entire period as well as on five grouped data series: the old Sharjah airport, the new Sharjah airport, and three overlapping 31-year data records (i.e., 1934-1964, 1960-1990, and 1984-2014).

Figure 4 depicts fitting of the linear regression trend and 10 -year moving average line to the annual rainfall observation data. The 10 -year moving average line is a powerful trend indicator showing that annual rainfalls exhibit high deviations from the annual mean (i.e., $103 \mathrm{~mm}$ ) and that rainfall variability is visibly marked by periodic intermittence between successive wet years and successive dry years. The trend associated with the whole period of observation (19342014) is not significant as can be seen from Figure 4 and the outcomes of the linear regression test (with positive linear regression slope $($ LRS $)=+0.051)$ and the Mann-Kendall test (with negative Sen's slope (SS) $=-0.034$ ). It is worth mentioning that the related MK test for the entire period was not statically significant ( $p$ value by all MK test options larger than 0.8 ), a result mainly driven by the characteristics of the period of 1934-1964 as shown hereafter. The results of Table 3 also indicate that despite the general preference to use nonparametric tests to analyze rainfall LRS can still give a better trend analysis compared to other tests. As seen from the statistical outcomes corresponding to the different time intervals, shown in Figure 5 and Table 3, there are combined and intermittent positive and negative trends. The downward linear trends associated with both old airport and new airport data sets should be interpreted with care. Despite the noticeable changes in the linear slopes of the yearly time series from $-3.2 \mathrm{~mm}$ per decade in 1977-2014 period to $-9.4 \mathrm{~mm}$ per decade in 1934-1976 period, the results do not implicate a continuous long-term negative impact of climate change on Sharjah's rainfall. In fact, the decline in rainfall 
TABLE 3: Mean annual rainfall trend: MK statistics (one-tailed with $5 \%$ significance interval) for the different aggregated periods with and without autocorrelation.

\begin{tabular}{lccccc}
\hline \multirow{2}{*}{$\begin{array}{l}\text { Tests' } \\
\text { outcomes }\end{array}$} & LRS & SS & \multicolumn{3}{c}{$p$ value $(\alpha=5 \%)$} \\
& $\mathrm{mm} / \mathrm{yr}$ & $\mathrm{mm} / \mathrm{yr}$ & $\begin{array}{c}\text { MK } \\
\text { Std. }\end{array}$ & $\begin{array}{c}\text { MK } \\
\text { Y\&W }\end{array}$ & $\begin{array}{c}\text { MK } \\
\text { H\&R }\end{array}$ \\
\hline $1934-2014$ & +0.051 & -0.034 & 0.922 & 0.797 & 0.9260 \\
$1934-1976$ & $-\mathbf{0 . 3 2}$ & $-\mathbf{0 . 4 5}$ & 0.445 & 0.014 & 0.166 \\
$1977-2014$ & -0.94 & -0.87 & 0.484 & 0.124 & 0.389 \\
$1934-1964$ & +0.58 & -0.026 & 0.986 & 0.968 & 0.986 \\
$1960-1990$ & $+\mathbf{1 . 4 0}$ & $\mathbf{+ 1 . 3 6}$ & 0.399 & 0.002 & 0.141 \\
$1984-2014$ & -0.93 & -0.60 & 0.711 & 0.510 & 0.604 \\
$1986-2014$ & $-\mathbf{2 . 3 7}$ & $\mathbf{- 2 . 5 2}$ & 0.161 & 0.0016 & 0.0036 \\
\hline
\end{tabular}

${ }_{1} p$ value calculated using standard Mann-Kendall test.

${ }^{2} p$ value calculated using Monte Carlo Simulation taking autocorrelation into account by the methodof Yue and Wang [16].

${ }^{3} p$ value calculated using Monte Carlo Simulation taking autocorrelation into account by the method of Hamed and Rao [17].

${ }^{4}$ The values of LRS and SS in bold correspond to a statistically significant trend with reference to one or more aforementioned MK tests.

amount was perceptible over several discontinuous periods, explicitly during 1944-1954, 1963-1974, and 1998-2008, as can be clearly identified from the 10 -year moving average line. Rainfall decrease in 1984-2014 period (LRS $=-9.3 \mathrm{~mm}$ per decade) is apparently equivalent to the drop during the 1977-2014 period (i.e., new airport data set). Nevertheless, the period witnesses the most demarcating drop in rainfall and reached unprecedented records during 1986-2014 period with negative LRS of $-25.4 \mathrm{~mm}$ per decade. This corresponds to over $22 \%$ drop from the annual mean. The outcomes for this particular period are statistically significant, as verified from the results of the MK tests presented in Table 3 (SS = $-2.52 \mathrm{~mm} / \mathrm{yr}$ ). However, looking at the alternating wet and long dry years revealed by all periods' 10 -year moving average lines and results of extreme rainfall periodicity in Section 3.3 hereafter, it is anticipated that this situation will be reversed in near few years. It is also worth mentioning that the ongoing vigorous rainfall modifications and cloud seeding activity in United Arab Emirates can also play a role to reverse this negative trend. For instance, in winter 2016 by the month of April about 77 seeding operations were performed and forecasted to have played a significant part to stimulate March 2016 rainfall of $287 \mathrm{~mm}$ in 24 hours as recorded between Dubai and Al-Ain cities [63].

3.2. Seasonal and Monthly Rainfall Trends and Variability. To capture long-term impacts of climate change, several assessments on seasonal and monthly rainfall data were carried out over the six aggregated periods. As shown in Table 4, drop in annual rainfall was mainly driven by the longterm decline in winter trends observed to continuously occur over the successive periods. Figures 6(a) and 6(b) show clear changes in trends' negative alteration between 1934-1976 period and 1977-2014 period, respectively. The decreasing trend is statistically significant as shown from the MK test's $p$ value obtained after Monte Carlo Simulation taking serial correlation into consideration using the method of Yue and Wang [16]. Sen's slopes for these two periods ( $S S=-0.46$ and $\mathrm{SS}=-1.18 \mathrm{~mm} / \mathrm{yr}$ ) and linear regression slopes (LRS = -0.30 and LRS $=-1.20 \mathrm{~mm} / \mathrm{yr}$ ) are evidently in the same range and are in complete agreement. Most demarcating is the downward slope of $-2.93 \mathrm{~mm} / \mathrm{yr}$ during 1986-2014 winter rainfall (i.e., Sen's slope $(\mathrm{SS})=-2.98 \mathrm{~mm} / \mathrm{yr}$ with $\mathrm{MK} p$ value $\leq 0.001)$ compared to $-0.81 \mathrm{~mm} /$ yr during $1934-1964$ period $(\mathrm{SS}=-0.95 ; p$ value $=+0.003)$ and upward slope of $+2.05 \mathrm{~mm} / \mathrm{yr}(\mathrm{SS}=+1.82$; $p$ value $<0.0001)$ during $1960-1990$ period.

As mentioned earlier, to assess changes in monthly rainfall trends, linear regression analysis, standard Mann-Kendall (MK) test, and seasonal MK (S-MK) test for each month were performed in parallel. It is worth mentioning that among the three options of Mann-Kendall test analyses (i.e., estimation of the test $p$ value with and without autocorrelation) the results were statistically more significant when using the option of Yue and Wang [16] to take serial correlation into account. To show the long-term climate impacts, reported in Table 5 are the monthly results for 1934-2014 (all data), 19341976 (old airport), and 1977-2014 (new airport) periods.

It is clear from the results of S-MK tests that winters' declining trends over the different periods between 1977 and 2014 were largely affected by the drop in February and March rainfalls. As a matter of fact, all options of the MK test and S-MK test are in agreement that no statistically significant trend could be captured, except for the months of February and March. Over time Sen's slope for February declined from LRS $=-0.07(S S=-0.001)$ to $L R S=-0.98(S S=-0.279)$ and March rainfall declined from LRS $=+0.04(\mathrm{SS}=-0.036)$ to LRS $=-0.67(\mathrm{SS}=-0.303) \mathrm{mm} / \mathrm{yr}$ over $1934-1976$ and $1977-$ 2014 periods, respectively. This continuing decline in trends over time was further stressed by the seasonal Sen's slope for March and April. Though the high S-MK $p$ values suggest that the seasonal tests are not statistically highly significant, the downward trend in March rainfalls is by itself alarming with regard to future water availability. Owing to the fact that Sharjah City receives most of its rainfall during March, practically any significant change in this month may later lead to long-term change in annual trends and the occurrence of extreme events (i.e., drought and floods). January's trend was found to be intermittent from a period to another. However, a closer look over 1986-2014 period (LRS $=-0.15$, SS $=-0.006$, and seasonal $\mathrm{SS}=-0.32$ ) reveals that the long-term appearing positive trend was mainly driven by the wet seasons in the late 1990s.

In contrast to other months, a long-term trend of December rainfalls showed positive trends of $+2.5 \mathrm{~mm} / \mathrm{yr}$ over $1977-$ 2014 period compared to $+0.5 \mathrm{~mm} / \mathrm{yr}$ over $1934-1976$ period. This increasing trend is probably associated with the net increase in the number of rainy days during December. Rainfalls events during the period from May to November are sporadic and bring about considerably small amount of rainfall. Thus, as shown in Table 5, owing to the erratic events in those months, seasonal MK test could not be performed.

With reference to Kendall's $\tau$ obtained from the monthly MK tests, though quite small, it probably suggests rain variability during the rainy season. To assess this assumption 


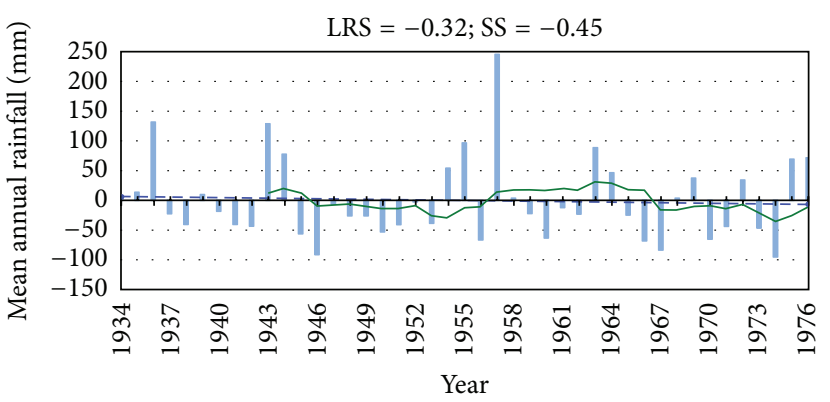

_. Annual deviation from mean

$\rightarrow-\rightarrow$ Linear regression line

- 10-year moving average

(a) 1934-1976: old Sharjah airport

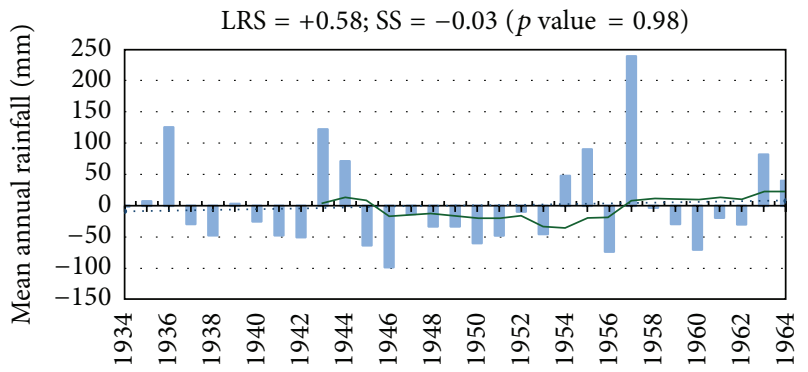

Year

- Annual deviation from mean

..... Linear regression trend

- 10-year moving average

(c) 1934-1964 period

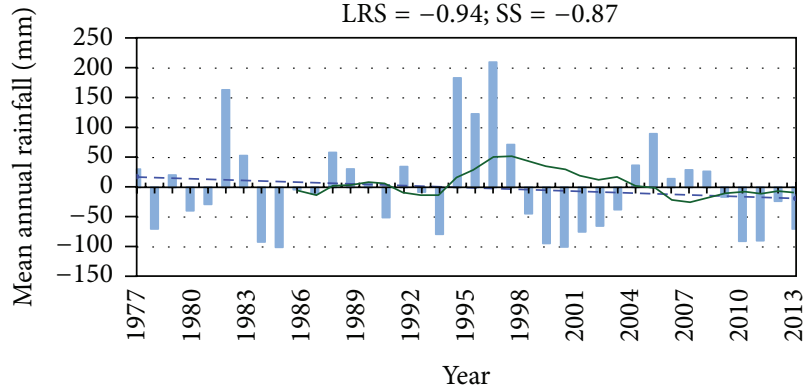

Annual deviation from mean

$\ldots$ Linear regression line

_ 10-year moving average

(b) 1977-2014: new Sharjah airport

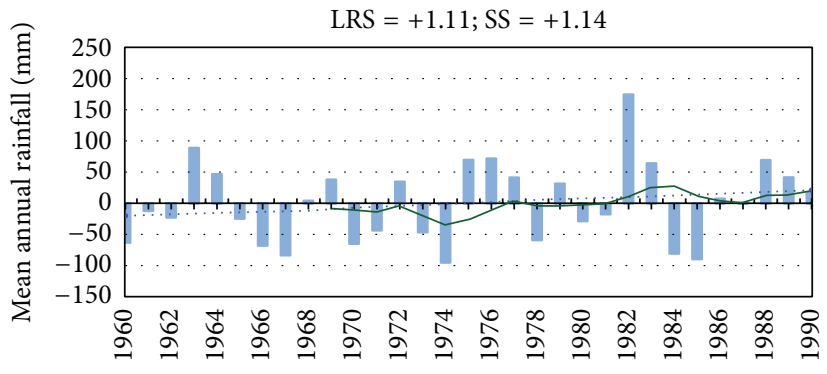

Year

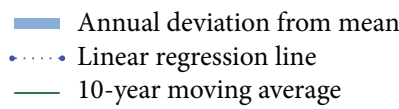

(d) 1960-1990 period

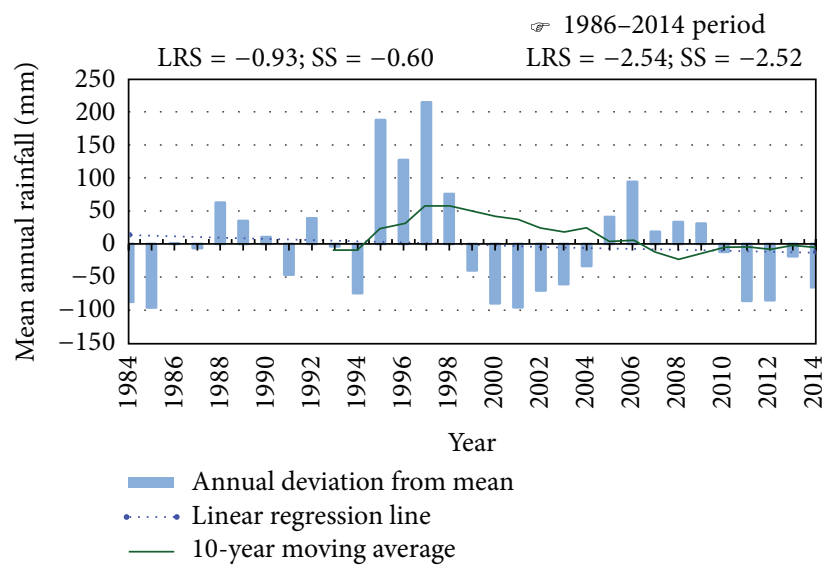

(e) 1984-2014 period

FIGURE 5: Mean annual precipitation and equivalent linear regression trend line and 10-year moving average line plotted for the different aggregated data sets: (a) 1934-1976, (b) 1977-2014, (c) 1934-1964, (d) 1960-1990, and (e) 1984-2014.

and set a comparative baseline in assessing monthly rainfall variations, the monthly peak average evaluated for the whole period (1934-2014) was compared to the peak rainfall over other periods as plotted in Figure 7. The results show that peak monthly rainfalls differ significantly over time. Surprisingly, clear propagation of peak monthly rainfall can be observed at a rate of approximately 1 month per 2 decades. This notable persistent long-term change in the occurrence of peak rainfalls calls for further in-depth analysis of potential climate change issues over Sharjah City.

3.3. Rainfall Frequency, Periodicity, and Extreme Events Analysis. In addition to frequency analysis of annual rainfall events (Figures 8 and 9), Fast Fourier Transform is applied to study the potential periodicity in extreme events (Figure 10). 
TABLE 4: Short-term and long-term seasonal trend analysis by linear regression and Mann-Kendell tests(one-tailed with $5 \%$ significance interval).

Method

Linear regression trend test Mann-Kendall trend test

\begin{tabular}{|c|c|c|c|c|c|c|c|c|c|}
\hline \multirow[t]{2}{*}{ Period } & \multirow{3}{*}{$\begin{array}{c}\text { 1934-1976 } \\
\text { LRS }^{*} \\
\mathrm{~mm} / \mathrm{yr}\end{array}$} & \multirow{3}{*}{$\begin{array}{c}\text { 1977-2014 } \\
\text { LRS } \\
\mathrm{mm} / \mathrm{yr}\end{array}$} & \multirow{3}{*}{$\begin{array}{c}\text { 1986-2014 } \\
\text { LRS } \\
\mathrm{mm} / \mathrm{yr}\end{array}$} & \multicolumn{2}{|c|}{ 1934-1976 } & \multicolumn{2}{|c|}{ 1977-2014 } & \multicolumn{2}{|c|}{ 1986-2014 } \\
\hline & & & & $\mathrm{SS}^{*}$ & $p$ value & SS & $p$ value & SS & $p$ value \\
\hline & & & & $\mathrm{mm} / \mathrm{yr}$ & $\alpha=5 \%$ & $\mathrm{~mm} / \mathrm{yr}$ & $\alpha=5 \%$ & $\mathrm{~mm} / \mathrm{yr}$ & $\alpha=5 \%$ \\
\hline Winter & -0.29 & -1.20 & -2.93 & -0.46 & 0.052 & -1.18 & 0.004 & -2.98 & $<0.0001$ \\
\hline Spring & 0.24 & -0.05 & 0.10 & 0.00 & 0.014 & 0.0004 & 0.322 & 0.00 & 0.918 \\
\hline Summer & 0.02 & 0.23 & 0.11 & 0.00 & 0.002 & 0.00 & 0.809 & 0.00 & 0.003 \\
\hline Autumn & -0.29 & 0.08 & 0.19 & 0.00 & 0.213 & 0.00 & $<0.0001$ & 0.00 & 0.000 \\
\hline Period & $1934-1964$ & 1960-1990 & 1984-2014 & \multicolumn{2}{|c|}{$1934-1964$} & \multicolumn{2}{|c|}{$1960-1990$} & \multicolumn{2}{|c|}{$1984-2014$} \\
\hline Winter & -0.81 & 2.05 & -1.50 & -0.96 & 0.003 & 1.82 & $<0.0001$ & -1.46 & 0.026 \\
\hline Spring & 1.30 & -0.56 & 0.16 & 0.0006 & 0.019 & 0.00 & 0.822 & 0.00 & 0.102 \\
\hline Summer & 0.12 & -0.04 & 0.16 & 0.0005 & $<0.0001$ & 0.00 & 0.326 & 0.00 & 0.242 \\
\hline Autumn & -0.02 & -0.06 & 0.24 & 0.00 & $<0.0001$ & 0.00 & 0.122 & 0.00 & $<0.0001$ \\
\hline
\end{tabular}

${ }^{*}$ LRS: linear regression slope; SS: Sen's slope; negative and positive signs of slope indicate a decreasing trend and an increasing trend, respectively. All tests' slopes are in $\mathrm{mm} / \mathrm{year}$.

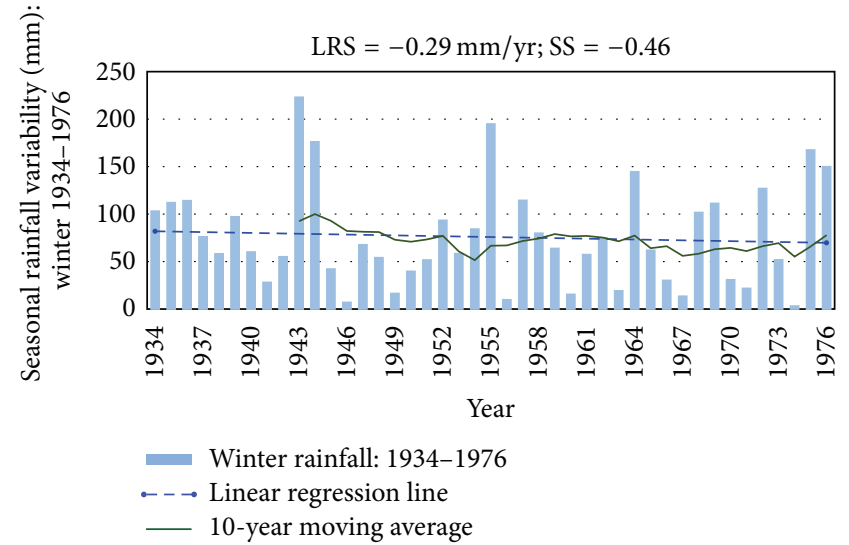

(a)

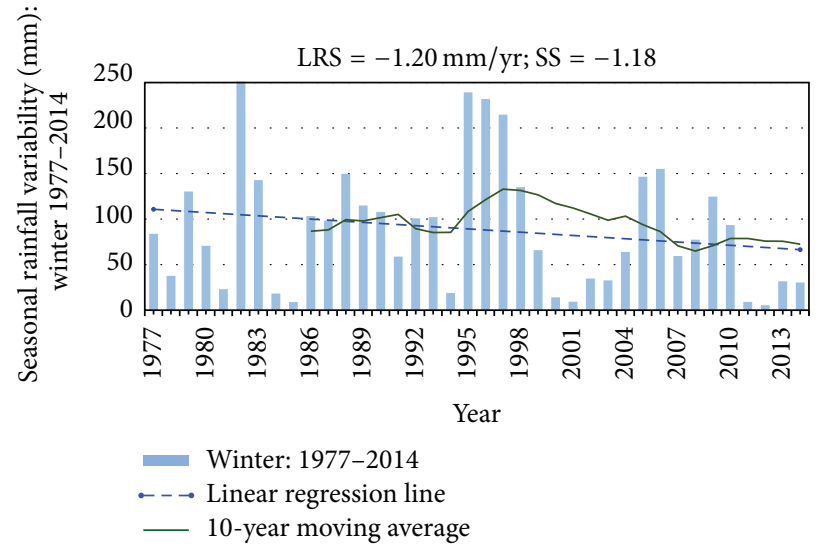

(b)

FIGURE 6: Long-term winter rainfall trends (dashed line) and 10-year moving average variability (solid line): (a) 1934-1976 period and (b) 1977-2014 period.

Figure 8 shows rainfall frequency analysis of old Sharjah airport and new Sharjah International Airport rainfall data sets. The figure was produced by normalizing the annual rainfall and by associating the normalized value with its probability to calculate the return period. The results suggest that extreme rainfall pattern is worsening (i.e., amount of rainfall during high frequency events is decreasing while it is increasing during low frequency events). This finding for Sharjah City is in accordance with the findings of many researchers worldwide and has been linked with climate change due to global warming $[6,64,65]$. Moreover, based on the predictions of General Circulation Models for climate [66], similar impacts of climate change on rainfall pattern can be expected in other surrounding cities of Sharjah City. In fact, the exceedance probability distribution results (normal
(Figure 9(a)) and log-Gumbel (Figure 9(b))) also suggest that the recurrence intervals and frequency of extreme events (drought and flood) are increasing. The findings of Figures 8 and 9 can be locally interpreted by an increasing number of successive drought years intermitted by severe flood events. As can be seen from Figure 8, the normalized annual precipitations for the period of 1977-2014 are higher when compared to those of the period of 1934-1976 for the same return periods. This demarcation of lines can be interpreted in association with the results of Figure 9 as higher occurrence of extreme precipitations (flood events) during 1977-2014 period if compared to 1934-1976 period for the same return period. In contrast, the trend is inversed for shorter return periods ( 2 year or shorter), where normalized annual precipitations for the period of 1977-2014 are found to 


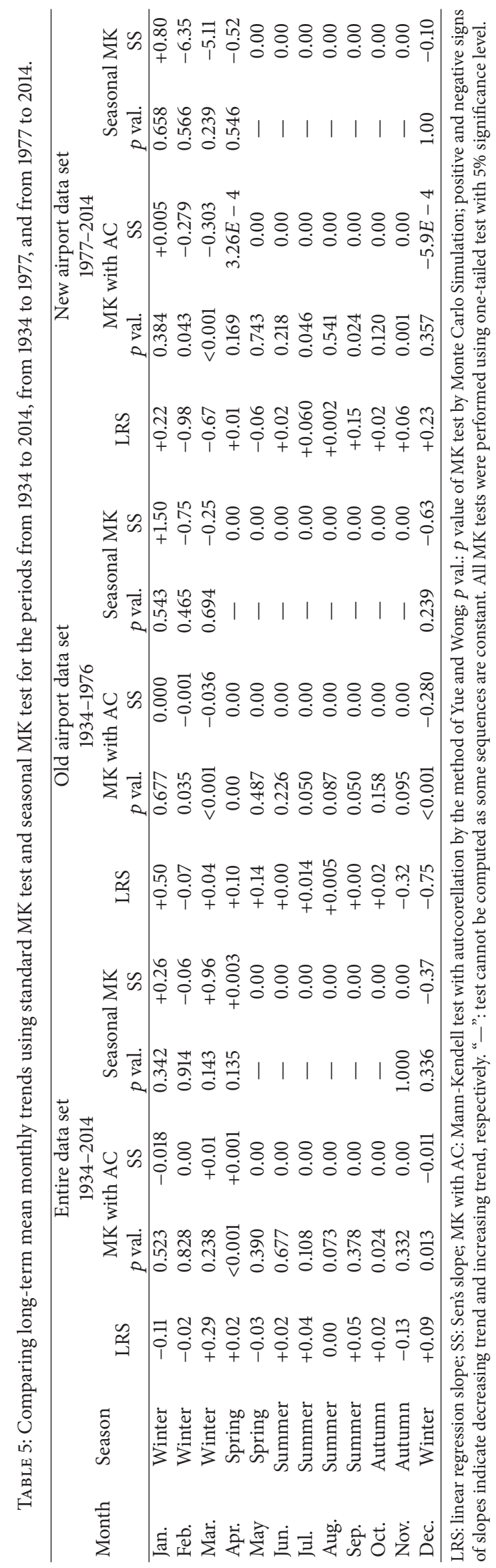




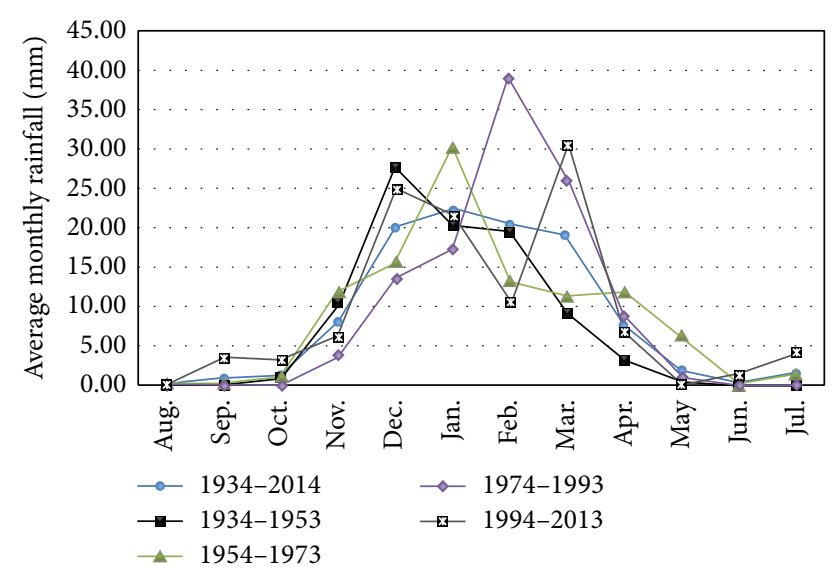

FIGURE 7: Variability in monthly peak rainfall over different time lines in Sharjah City.

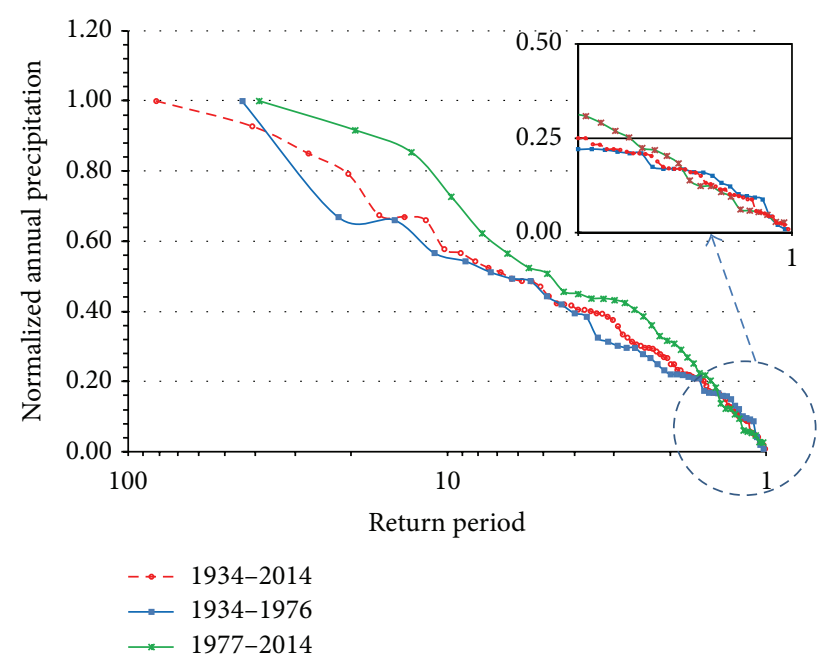

FIGURE 8: Comparison of rainfall frequency (return period) in terms of normalized annual rainfall events.

be slightly lower than those of the period of 1934-2014. With reference to Figure 9, this can be interpreted as the occurrence of successive years of drought with a short return period.

To assess the periodicity, Figure 10 shows the normalized power spectrum of annual rainfall. Data from old Sharjah airport exhibit multiple peaks. Peak frequency of 0.279 is associated with a rainfall event repeating itself in 3.6 years, while the 2nd peak appears to be centered between 0.046 and 0.1395 , which corresponds to periodicity of 7.2 to 21.7 years. On the other hand, new Sharjah airport's data show only one distinct peak at a frequency of 0.079 (12.6 years) closer to the 2nd peak of old data and eliminate the periodicity of the lower frequency rainfall event.

\section{Summary and Conclusion}

In the present study, potential impacts of climate change on the long-term rainfall trends over Sharjah City in United Arab Emirates using 81-year monthly records were examined.

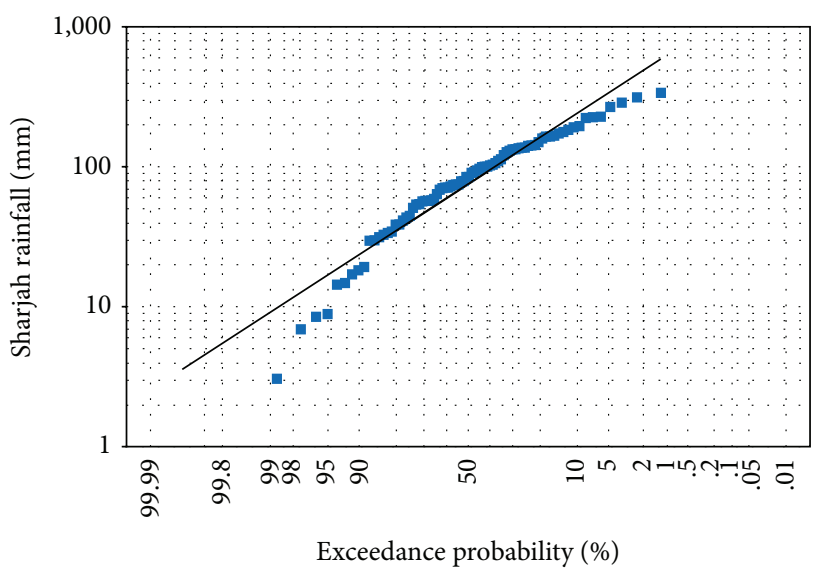

(a) Normal probability distribution

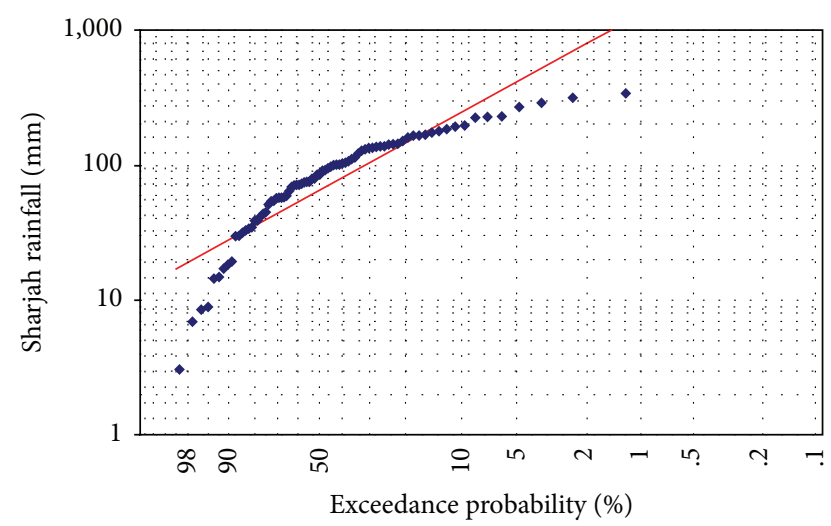

(b) Log-Gumbel probability distribution

FIGURE 9: Sharjah rainfall exceedance probability using (a) normal probability distribution and (b) log-Gumbel probability distribution.

Long-term and short-term rainfall trends using parametric and nonparametric statistical measures, namely, monotonic linear regression trend analysis, Mann-Kendall trend test, and Mann-Kendall seasonal trend, with and without considering serial correlation powered by Sen's slope and 10-year moving average, are evaluated in parallel. To fully capture annual, seasonal, and monthly rainfall trends and variability, data were divided into six aggregated periods. It is worth mentioning that when a clear trend occurs (such as in winter months and seasons), linear regression analysis and Sen's slope corresponding to the Mann-Kendall test (particularly those evaluated using Monte Carlo Simulation with serial correlation by the method of Yue and Wong) are in full agreement. In other words, the results showed that despite the dominant preference of nonparametric test to assess trends in climate data the LRS can still give equally good trend analysis compared to other tests.

In general, it was found that annual rainfall trend over Sharjah City is continuously decreasing over time. The rate of decrease in annual rainfall has accelerated to approximately $-9.3 \mathrm{~mm}$ per decade (data of 1977-2014) in contrast to $-3.2 \mathrm{~mm}$ per decade (data of 1937-1976). Most demarcating was the drawdown annual trend during 1986-2014 period of 

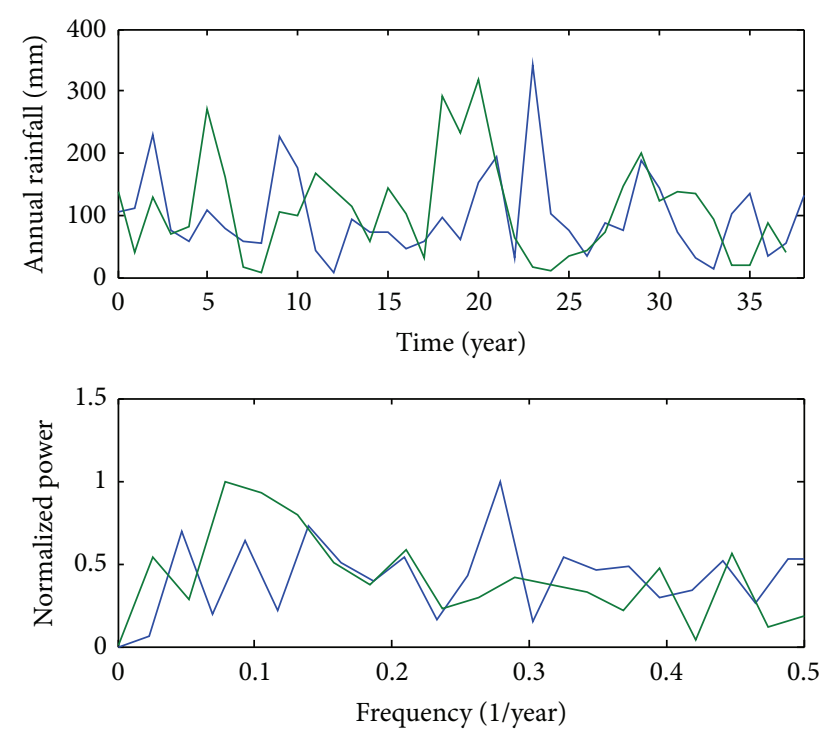

FIGURE 10: Normalized power spectrum estimated from annual rainfall using Fast Fourier Transform analysis (blue line: 1934-1976; green line: 1977-2014).

about $-24 \mathrm{~mm} /$ decade. This annual decline in rainfall was mainly driven by clear successive drops in winter rainfalls suggesting an overall risk on water availability which can potentially drop by over $20 \%$ from the annual mean if the trend decline persists. In monthly rainfall trend tests, while most months showed nonsignificant trend, the months of April and March indicated a significant decreasing trend of rainfall. This finding is important because Sharjah City receives most of its rainfall during this period. In other words, any significant change in March and April rainfall may lead to long-term change in annual trends. Furthermore, analysis of monthly precipitation showed clear propagation of peak monthly rainfall at a rate of approximately 1 month per 2 decades. This notable persistent long-term change in the occurrence of peak rainfalls calls for further in-depth analysis of potential climate change issues and risks over Sharjah City.

The 10-year moving average analysis highlights the fact that rainfall patterns are characterized by long periods of droughts which are intercepted by extreme heavy rainfall events of short interval of recurrence. Frequency analysis potentially indicates that the extreme rainfall patterns are worsening. Fast Fourier Transform analysis implies that under changing climate the periodicity of high rainfall events is shifting toward low frequency. This is confirmed by the recurring flash flood witnessed in recent decades.

To sum up, analysis of long-term rainfall at Sharjah City shows a decreasing trend in rainfall and, in the light of present evidence, water resources preparedness, development, and management strategies under changing climate are recommended as a way forward for sustainability. Flood risk management must be also conceived as an integrated part of the strategic plans of the Emirate of Sharjah for climate changes adaptation and mitigation. Further, investigations and more comprehensive analysis of the impact of climate change in UAE using wider spectrum of temporal and spatial climatic data are strongly recommended.

\section{Competing Interests}

The authors declare that there are no competing interests regarding the publication of this paper.

\section{Acknowledgments}

The authors gratefully acknowledge funding support provided through the Sustainable Civil Infrastructure Systems (SCIS) Research Group and the Research Institute for Science and Engineering (RISE) of the University of Sharjah. The authors deeply appreciate the support of the Sharjah Aviation Authority and all its members at the Meteorologic Office for providing the valuable data and support that made this study possible.

\section{References}

[1] J. T. Houghton, L. G. Meira Filho, B. A. Callander et al., Climate Change 1995: The Science of Climate Change. Working Group I, Second Assessment Report of the Intergovernmental Panel on Climate Change (IPCC), Cambridge University Press, Cambridge, UK, 1996.

[2] D. R. Easterling, G. A. Meehl, C. Parmesan, S. A. Changnon, T. R. Karl, and L. O. Mearns, "Climate extremes: observations, modeling, and impacts," Science, vol. 289, no. 5487, pp. 20682074, 2000 .

[3] J. Berkoff, A Strategy for Managing Water in the Middle East and North Africa, IBRD/World Bank, Washington, DC, USA, 1994.

[4] IPCC, Climate Change 2007: Impacts, Adaptation and Vulnerability. Contribution of Working Group II to the Fourth Assessment Report of the Intergovernmental Panel on Climate Change, Cambridge University Press, Cambridge, UK, 2007.

[5] D. Verner, "Adaptation to a changing climate in the Arab Countries: a case for adaptation governance and leadership in building climate resilience," MENA Development Report, World Bank Publications, 2012.

[6] IPCC, "Climate change 2013: the physical science basis," in Contribution of Working Group I to the Fifth Assessment Report of the Intergovernmental Panel on Climate Change, Cambridge University Press, Cambridge, UK, 2013.

[7] J. S. Pal and E. A. B. Eltahir, "Future temperature in southwest Asia projected to exceed a threshold for human adaptability," Nature Climate Change, vol. 6, no. 2, pp. 197-200, 2016.

[8] G. A. Meehl, J. M. Arblaster, and C. Tebaldi, "Contributions of natural and anthropogenic forcing to changes in temperature extremes over the United States," Geophysical Research Letters, vol. 34, no. 19, Article ID L19709, 2007.

[9] J. Sillmann and E. Roeckner, "Indices for extreme events in projections of anthropogenic climate change," Climatic Change, vol. 86, no. 1-2, pp. 83-104, 2008.

[10] L. V. Alexander and J. M. Arblaster, "Assessing trends in observed and modelled climate extremes over Australia in relation to future projections," International Journal of Climatology, vol. 29, no. 3, pp. 417-435, 2009. 
[11] B. A. Malmgren, R. Hulugalla, Y. Hayashi, and T. Mikami, "Precipitation trends in Sri Lanka since the 1870s and relationships to El Niño-southern oscillation," International Journal of Climatology, vol. 23, no. 10, pp. 1235-1252, 2003.

[12] S. Luis, L. S. Pereira, I. Cordery, and I. Iacovides, "Coping with water scarcity," Technical Documents in Hydrology 58, UNESCO IHP-VI, Paris, France, 2002.

[13] G. Choi, D. Collins, G. Ren et al., "Changes in means and extreme events of temperature and precipitation in the AsiaPacific Network region, 1955-2007," International Journal of Climatology, vol. 29, no. 13, pp. 1906-1925, 2009.

[14] M. I. P. De Lima, S. C. P. Carvalho, J. L. M. P. De Lima, and M. F. E. S. Coelho, "Trends in precipitation: analysis of long annual and monthly time series from mainland Portugal," Advances in Geosciences, vol. 25, pp. 155-160, 2010.

[15] R. E. Benestad, "Association between trends in daily rainfall percentiles and the global mean temperature," Journal of Geophysical Research: Atmospheres, vol. 118, pp. 1-9, 2013.

[16] S. Yue and C. Wang, "The Mann-Kendall test modified by effective sample size to detect trend in serially correlated hydrological series,' Water Resources Management, vol. 18, no. 3, pp. 201-218, 2004.

[17] K. H. Hamed and A. R. Rao, "A modified Mann-Kendall trend test for autocorrelated data," Journal of Hydrology, vol. 204, no. 1-4, pp. 182-196, 1998.

[18] M. J. Manton, P. M. Della-Marta, M. R. Haylock et al., "Trends in extreme daily rainfall and temperature in Southeast Asia and the South Pacific: 1961-1998," International Journal of Climatology, vol. 21, no. 3, pp. 269-284, 2001.

[19] XB. Zhang, E. Aguilar, S. Sensoy et al., "Trends in Middle East climate extreme indices from 1950 to 2003," Journal of Geophysical Research: Atmospheres, vol. 110, no. D22, 2005.

[20] M. G. Donat, T. C. Peterson, M. Brunet et al., "Changes in extreme temperature and precipitation in the Arab region: long-term trends and variability related to ENSO and NAO," International Journal of Climatology, vol. 34, no. 3, pp. 581-592, 2013.

[21] A. Longobardi and P. Villani, "Trend analysis of annual and seasonal rainfall time series in the Mediterranean area," International Journal of Climatology, vol. 30, no. 10, pp. 1538-1546, 2010.

[22] T. Caloiero, R. Coscarelli, E. Ferrari, and M. Mancini, "Trend detection of annual and seasonal rainfall in Calabria (Southern Italy)," International Journal of Climatology, vol. 31, no. 1, pp. 4456, 2011.

[23] C. Clarke, M. Hulley, J. Marsalek, and E. Watt, "Stationarity of AMAX series of short-duration rainfall for long-term canadian stations: detection of jumps and trends," Canadian Journal of Civil Engineering, vol. 38, no. 11, pp. 1175-1184, 2011.

[24] L. Miao, X. Jun, and M. Dejuan, "Long-term trend analysis of seasonal precipitation for Beijing, China," Journal of Resources and Ecology, vol. 3, no. 1, pp. 64-72, 2012.

[25] D. Ambun, B. T. Azlai, E. B. Phuah et al., Statistical and Trend Analysis of Rainfall Data in Kuching, Sarawak from 19682010, Research Publication no. 6, Malaysian Meteorological Department, Ministry of Science, Technology and Innovation, 2013.

[26] K. Arnbjerg-Nielsen, P. Willems, J. Olsson et al., "Impacts of climate change on rainfall extremes and urban drainage systems: a review," Water Science and Technology, vol. 68, no. 1, pp. 16-28, 2013.
[27] A. Y. Kwarteng, A. S. Dorvlo, and G. T. V. Kumar, "Analysis of a 27-year rainfall data (1977-2003) in the Sultanate of Oman," International Journal of Climatology, vol. 29, no. 4, pp. 605-617, 2009.

[28] N. L. Gunawardhana and G. A. Al-Rawas, "Trends in extreme temperature and precipitation in Muscat, Oman," in Proceedings of the 6th IAHS-EGU International Symposium on Integrated Water Resources Management (ICWRS '14), vol. 364, pp. 57-63, The International Association of Hydrological Sciences (IAHS), Bologna, Italy, June 2014.

[29] R. Modarres and V. de Paulo Rodrigues da Silva, "Rainfall trends in arid and semi-arid regions of Iran," Journal of Arid Environments, vol. 70, no. 2, pp. 344-355, 2007.

[30] Y. Dinpashoh, A. Fakheri-Fard, M. Moghaddam, S. Jahanbakhsh, and M. Mirnia, "Selection of variables for the purpose of regionalization of Iran's precipitation climate using multivariate methods," Journal of Hydrology, vol. 297, no. 1-4, pp. 109-123, 2004.

[31] T. Raziei, J. Daryabari, I. Bordi, and L. S. Pereira, "Spatial patterns and temporal trends of precipitation in Iran," Theoretical and Applied Climatology, vol. 115, no. 3-4, pp. 531-540, 2014.

[32] M. Almazroui, M. N. Islam, P. D. Jones, H. Athar, and M. A. Rahman, "Recent climate change in the Arabian Peninsula: seasonal rainfall and temperature climatology of Saudi Arabia for 1979-2009," Atmospheric Research, vol. 111, pp. 29-45, 2012.

[33] H. Hasanean and M. Almazroui, "Rainfall: features and variations over Saudi Arabia, a review," Climate, vol. 3, no. 3, pp. 578-626, 2015.

[34] A. Al-Mamoon and A. Rahman, "Identification of rainfall trends in Qatar," in Proceedings of the in International Conference on Environmental Systems Science and Engineering, vol. 8, no. 12 of part 5, Sydney, Australia, 2012.

[35] Z. S. Rizk and A. S. AlSharhan, "Water resources in the United Arab Emirates," in Developments in Water Science: Water Resources Perspectives: Evaluation, Management and Policy, A. S. AlSharhan, Ed., pp. 245-264, Elsevier, New York, NY, USA, 2003.

[36] M. F. Al-Rashed and M. M. Sherif, "Water resources in the GCC countries: an overview," Water Resources Management, vol. 14, no. 1, pp. 59-75, 2000.

[37] A. A. Murad, "An overview of conventional and nonconventional water resources in arid region: assessment and constrains of the United Arab Emirates (UAE)," Journal of Water Resource and Protection, vol. 2, no. 2, pp. 181-190, 2010.

[38] S. Szabo, "The water challenge in the UAE," Policy Brief 29, Dubai School of Government, 2011.

[39] M. Al-Mulla, "UAE state of the water report," in Proceedings of the 2nd Arab Water Forum, Cairo, Egypt, November 2011.

[40] M. Sherif, M. Almulla, A. Shetty, and R. K. Chowdhury, "Analysis of rainfall, PMP and drought in the United Arab Emirates," International Journal of Climatology, vol. 34, no. 4, pp. 1318-1328, 2014.

[41] N. Bottomley, "Weather in the UAE," Tribulus, vol. 1, no. 2, pp. 16-18, 1991.

[42] G. R. Feulner, "Rainfall and climate records from Sharjah Airport: historical data for the study of recent climatic periodicity in the U.A.E," Bulletin Emirates Natural History Group, Tribulus, vol. 16, no. 1, pp. 1-9, 2006.

[43] J. R. Jones, J. S. Schwartz, K. N. Ellis, J. M. Hathaway, and C. M. Jawdy, "Temporal variability of precipitation in the Upper Tennessee Valley," Journal of Hydrology: Regional Studies, vol. 3, pp. 125-138, 2015. 
[44] R. Lázaro, F. S. Rodrigo, L. Gutiérrez, F. Domingo, and J. Puigdefábregas, "Analysis of a 30-year rainfall record (19671997) in semi-arid SE spain for implications on vegetation," Journal of Arid Environments, vol. 48, no. 3, pp. 373-395, 2001.

[45] B. Liebmann, R. M. Dole, C. Jones, D. Allured, and I. Blade, "Influence of choice of time period on global surface temperature trend estimates," Bulletin of the American Meteorological Society, vol. 91, pp. 1485-1491, 2010.

[46] D. W. Wayne, "Kolmogorov-Smirnov one-sample test," in Applied Nonparametric Statistics, pp. 319-330, PWS-Kent, Boston, Mass, USA, 2nd edition, 1990.

[47] T. W. Kirkman, "Statistics to use: Kolmogorov-Smirnov test," 1996, http://www.physics.csbsju.edu/stats/KS-test.html.

[48] E. L. Lehmann, Nonparametrics: Statistical Methods Based on Ranks, Springer, New York, NY, USA, 2006.

[49] T. C. Peterson, D. R. Easterling, T. R. Karl et al., "Homogeneity adjustments of in situ atmospheric climate data: a review," International Journal of Climatology, vol. 18, no. 13, pp. 14931517, 1998.

[50] H. Alexandersson, "A homogeneity test applied to precipitation data," Journal of Climatology, vol. 6, no. 6, pp. 661-675, 1986.

[51] R. M. Hirsch, D. R. Helsel, T. A. Cohn, and E. J. Gilroy, "Statistical analysis of hydrologic data," in Handbook of Hydrology, D. R. Maidment, Ed., chapter 17, pp. 11-37, McGraw Hill, New York, NY, USA, 1993.

[52] H. M. Kang and F. Yusof, "Homogeneity tests on daily rainfall series in Peninsular Malaysia," International Journal of Contemporary Mathematical Sciences, vol. 7, no. 1, pp. 9-22, 2012.

[53] M. N. Khaliq and T. B. M. J. Ouarda, "On the critical values of the standard normal homogeneity test (SNHT)," International Journal of Climatology, vol. 27, no. 5, pp. 681-687, 2007.

[54] S. Yue, P. Pilon, B. Phinney, and G. Cavadias, "The influence of autocorrelation on the ability to detect trend in hydrological series," Hydrological Processes, vol. 16, no. 9, pp. 1807-1829, 2002.

[55] S. Yue and P. Pilon, "A comparison of the power of the $t$ test, Mann-Kendall and bootstrap tests for trend detection," Hydrological Sciences Journal, vol. 49, no. 1, pp. 21-38, 2004.

[56] R. M. Hirsch, J. R. Slack, and R. A. Smith, "Techniques of trend analysis for monthly water quality data," Water Resources Research, vol. 18, no. 1, pp. 107-121, 1982.

[57] W. A. Freas and E. Sieurin, "A nonparametric calibration procedure for multi-source urban air pollution dispersion models," in Proceedings of the 5th Conference on Probability and Statistics in Atmospheric Sciences, American Meteorological Society, 1977.

[58] K. H. Hamed, "The distribution of Kendall's tau for testing the significance of cross-correlation in persistent data," Hydrological Sciences Journal, vol. 56, no. 5, pp. 841-853, 2011.

[59] R. M. Hirsch and J. R. Slack, "A nonparametric trend test for seasonal data with serial dependence," Water Resources Research, vol. 20, no. 6, pp. 727-732, 1984.

[60] G. A. Tularam and M. Ilahee, "Time series analysis of rainfall and temperature interactions in coastal catchments," Journal of Mathematics and Statistics, vol. 6, no. 3, pp. 372-380, 2010.

[61] J. G. M. Hasan, R. Alam, Q. N. Islam, and S. Hossain, "Frequency structure of major rainfall events in the north-eastern part of Bangladesh," Journal of Engineering Science and Technology, vol. 7, no. 6, pp. 690-700, 2012.

[62] WMO, "Detecting trend and other changes in hydrological data," in World Climate Data and Monitoring Programme (WCDMP)—45, Z. W. Kundzewicz and A. Robson, Eds., WMO/ TD-No. 1013, Geneva, Switzerland, May 2000, WMO, 2003.
[63] UAE-NCMS, Cloud Seeding Research: Studies and Assessment, United Arab Emirates National Center of Meteorology \& Seismology (SCMS), 2016, http://www.ncms.ae/en/ncms-bookdetails.html?id=03.

[64] IPCC, "Climate Change 2014: impacts, adaptation, and vulnerability. Part A: global and sectoral aspects," in Contribution of Working Group II to the Fifth Assessment Report of the Intergovernmental Panel on Climate Change, Cambridge University Press, Cambridge, UK, 2014.

[65] IPCC, Climate Change 2014: Impacts, Adaptation, and Vulnerability, Part B: Regional Aspects. Contribution of Working Group II to the Fifth Assessment Report of the Intergovernmental Panel on Climate Change, Cambridge University Press, Cambridge, UK, 2014.

[66] UAE-ME, "Initial national communication to the united nations framework convention on climate change," First National Communication Report, Ministry of Energy United Arab Emirates, Dubai, United Arab Emirates, 2006. 

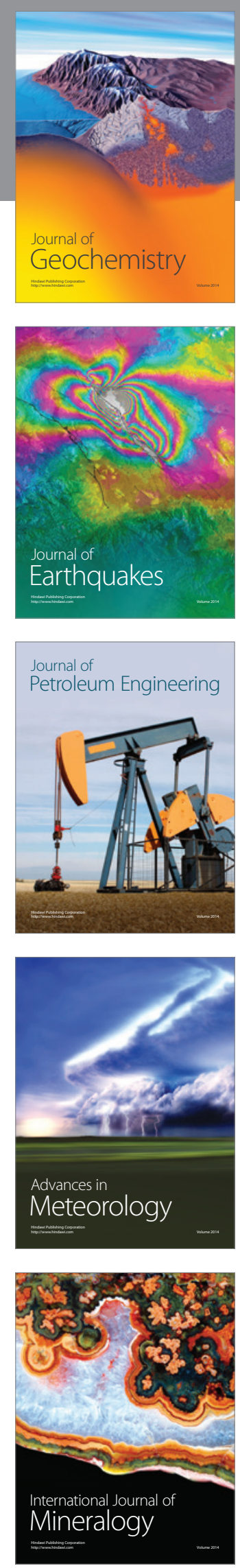
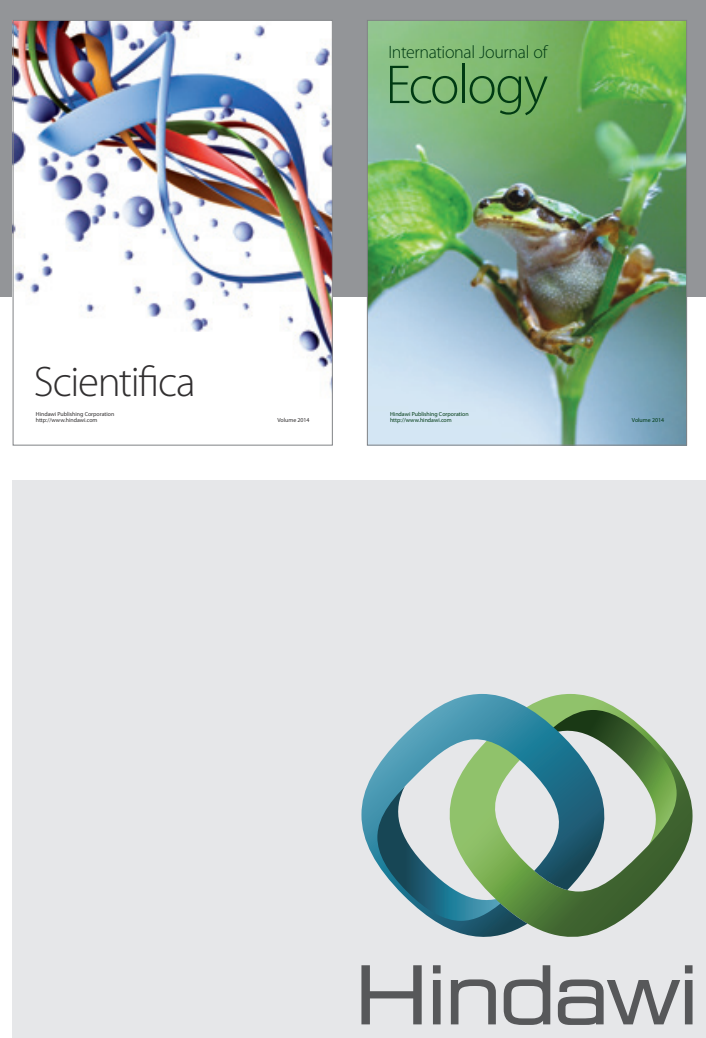

Submit your manuscripts at

http://www.hindawi.com
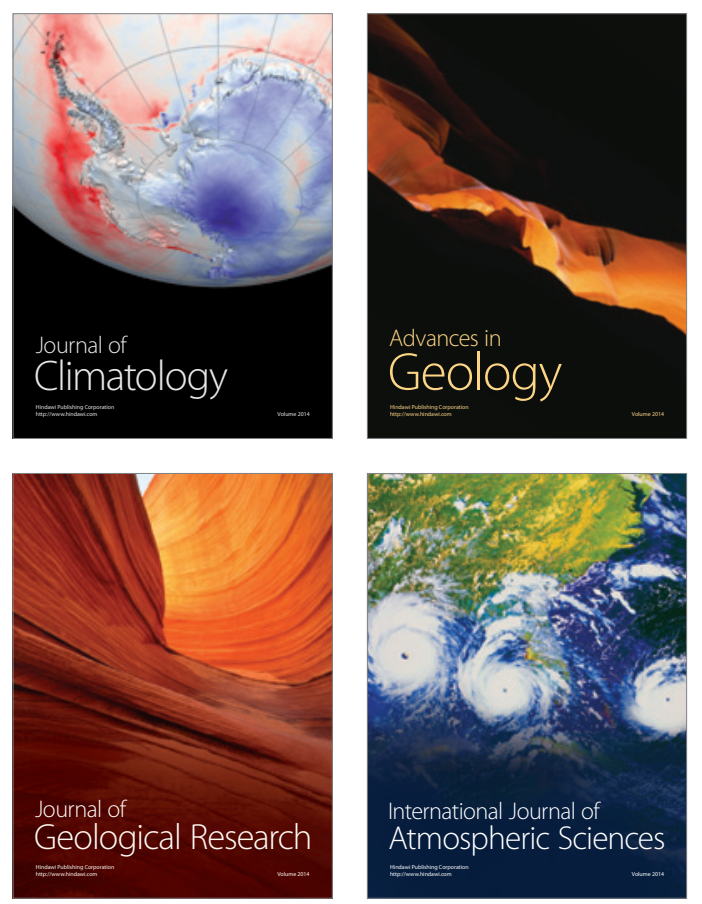

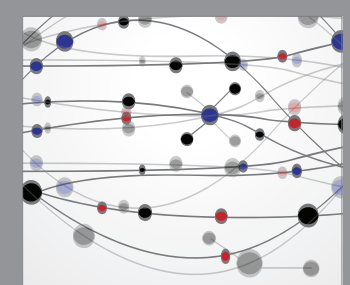

The Scientific

\section{World Journal}
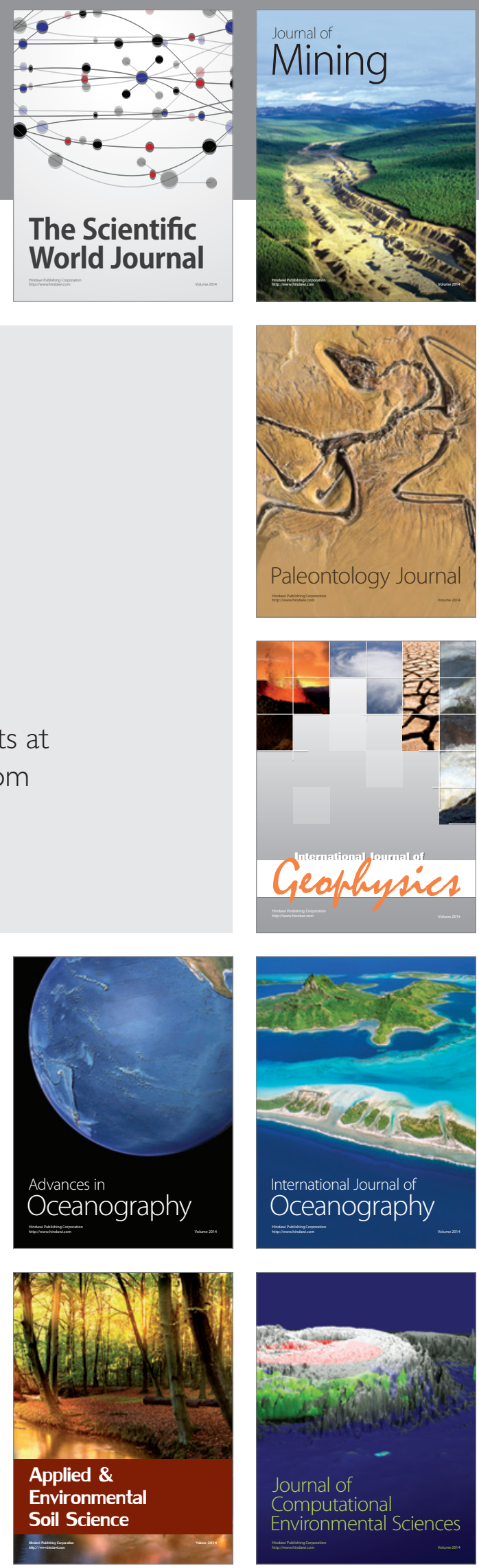